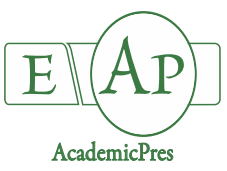

Salis C et al. (2021)

Notulae Botanicae Horti Agrobotanici Cluj-Napoca

Volume 49, Issue 2, Article number 12394

DOI: $10.15835 /$ nbha49212394

Research Article

\title{
Identification and quantification of phenolic compounds in fresh and processed table olives of cv. 'Kalamata'
}

\author{
Constantinos SALIS ${ }^{1}$, Ioannis E. PAPADAKIS ${ }^{2}$, \\ Marianna HAGIDIMITRIOU ${ }^{1 *}$
}

\author{
${ }^{1}$ Agricultural University of Athens, School of Food, Biotechnology and Development, Department of Biotechnology, Genetics \\ Laboratory,75Iera Odos 11855, Athens, Greece; saliskonstantinos@yahoo.com; marianna@aua.gr (*corresponding author) \\ ${ }^{2}$ Agricultural University of Athens, School of Plant Sciences, Department of Crop Science, Pomology Laboratory, \\ 75 Iera Odos 11855, Athens, Greece; papadakis@aua.gr
}

\begin{abstract}
Mediterranean diet is almost synonymous to the healthy lifestyle and diet nowadays. Some of the major components of the diet are the products of the olive tree, fruits and olive oil, which are classified as medical foods, due to their nutraceutical benefits and their protective properties against cancer, cardiovascular diseases, age-related diseases, neurodegenerative disorders and other diseases. The key contributors to these properties are the phenolic compounds such as hydroxytyrosol, tyrosol and oleuropein. Table olives are being processed with several methods in order to reduce the bitterness of the olive fruit and the impact of the processing on phenolic compounds has not been studied extensively. In the present study, changes in the concentration of the most important phenolic compounds were quantified in fresh, Greek-style and Spanish-style processed olive fruits of cv. 'Kalamata', using two different analytical methods for identification and quantification: highperformance liquid chromatography diode array detector (HPLC-DAD) and ultrahigh-performance liquid chromatography tandem mass spectrometry (LC-(ESI)-MS/MS). The phenolic compounds that were identified and quantified were hydroxytyrosol, tyrosol, verbascocide, rutin, oleuropein and luteolin. Both processing methods used altered the phenolic compounds concentration in 'Kalamata' olive fruits compared to untreated fruits. In both analytical methods, a statistically significant increase in verbascoside and hydroxytyrosol concentration and a statistically significant decrease in rutin concentration was observed in both, Greek-style and Spanish-style, processed olive fruits.
\end{abstract}

Keywords: HPLC-DAD; LC-(ESI)-MS/MS; Mediterranean diet; phenolic compounds; processing; table olives

\section{Introduction}

Plants are an inexhaustible source of bioactive compounds that in recent years have gained enormous interest in their therapeutic use. The scientific community has focused on the search for compounds from plant extracts to prevent and control a large number of diseases. Indicatively, it is reported that $50 \%$ of drugs aiming at fighting cancer come directly or indirectly from plant products (Kingston, 2011). Among the thousands of 
plant products, the products of the olive tree, extra virgin olive oil (EVOO) and olive fruits, historically play a particularly important social and economic role in the Mediterranean countries. The main area of cultivation is the Mediterranean region, where $90 \%$ of olive oil worldwide is consumed and $80 \%$ of the market share of exports is controlled (Bartolini and Petruccelli, 2002; Vasto et al., 2014). Olive tree products are a significant source of healthy fatty acids as part of the Mediterranean diet and considered as rich as in beneficial compounds 'superfoods' (Vasto et al., 2014; Gerber and Hoffman, 2015). The abundance of phenolic compounds in EVOO, such as polyphenols (Barbaro et al., 2014; Rigacci and Stefani, 2016), have been studied excessively over the years for their anti-microbial, antioxidant and anti-inflammatory action (Cicerale et al., 2012). Research has shown that the consumption of olive products is linked with the reduction of risk of several diseases, such as cardiovascular diseases (Esti et al., 1998), neurodegenerative diseases and diseases associated with aging (Khalatbary, 2013; Salis et al., 2020) and diabetes (Salas-Salvadó et al., 2014).

Of the bioactive compounds, phenolic compounds have gained interest in the scientific community in recent years, mainly due to their antioxidant and anti-inflammatory properties. Phenolic compounds are derived from the metabolism of primary products, such as carbohydrates, fats and amino acids, and are called secondary products due to their biosynthesis. The most important phenolic groups present in the olive fruit are phenolic acids, phenolic alcohols, flavonoids and secoiridoids (Macheix et al., 1990; Ryan and Robards, 1998; Soler-Rivas et al., 2000). The most important phenolic alcohols in the olive fruit are tyrosol and hydroxytyrosol (Macheix et al., 1990; Mazza and Miniati, 1993; Romero et al., 2002). The most frequently mentioned and important flavonoids in the olive fruit are luteolin and rutin (Esti et al., 1998; Ryan and Robards, 1998; Romani et al., 1999). The most prevalent secoiridoid found in the olive fruit is oleuropein, while verbascocide is the predominant phenolic acid. Hydroxytyrosol has been shown to have a wide range of biological effects, including anti-cancer, cardioprotective, anti-microbial, neuroprotective and other effects (Visioli et al., 2002; Parkinson and Cicerale, 2016; Tomé-Carneiro et al., 2016; Valenzuela et al., 2017; RoblesAlmazan et al., 2018). Oleuropein has a strong antioxidant activity, which is widely recognized and along with its anti-inflammatory properties, is considered to be the basis of anti-cancer, neuroprotective, cardioprotective and other actions (Visioli et al., 2002; Hassen et al., 2015; Basdeki et al., 2020). Tyrosol appears to be an effective antioxidant and has beneficial effects against hyper intention, atherosclerosis, heart failure, obesity and other actions (Di Benedetto et al., 2007; Chang et al., 2019; Salis et al., 2020). Rutin has demonstrated antioxidant, cardioprotective, anti-cancer, neuroprotective and other pharmacological properties (Janbaz et al., 2002; Nassiri-Asl et al., 2010; Richetti et al., 2011; Javed et al., 2012; Valenzuela et al., 2017). A growing body of research shows that lutein has antioxidant, anti-cancer, anti-inflammatory and neuroprotective properties (Lin et al., 2008; Qiao et al., 2012; Theoharides et al., 2015). Finally, verbascoside has demonstrated antiinflammatory properties and it has been suggested that it could has anti-cancer properties (Lee et al., 2006; Korkina, 2007; Lenoir et al., 2011; Akdemir et al., 2011).

The most important factors affecting the biosynthesis of phenolic compounds are genotype, tissue, growth stage, biotic factors, microclimate and cultivation techniques (Karakaya and Nehir, 1999). The processing method of the final products has also a significant effect on the phenolic compound concentration. Olive fruit processing methods affect the taste and can significantly alter the health properties of the olive fruit, mostly because different processing methods can lead to different capacity of hydrolysis products (Marsilio et al., 2005; Zoidou et al., 2010; Charoenprasert and Mitchell, 2012). The main methods of processing olive fruits which are designed to reduce oleuropein concentration, but consequently affect the other phenolic compounds, leading to a different phenolic compound profile, are: a) the Greek-style processing method: ripe olives are treated with brine, b) the Spanish-style processing method: unripe olives are treated with sodium hydroxide, fermented and pasteurized and c) the Californian- type processing method: unripe olives are treated with sodium hydroxide and air oxidation (Karkoula et al., 2012). The greatest volume of studies is based on the phenolic compound profile of olive oil, while the phenolic compound composition of the fruit is different, it changes after treatments and remains insufficiently explored (Boskou et al., 2005). 
In the past, several strategies of analysis and quantitation of phenolic compounds have been used for the products of the olive tree, but most of them have focused on olive oil (Bianco et al., 2003; Servili et al., 2004; Bendini et al., 2007; Carrasco-Pancorbo et al., 2007; Fu et al., 2009). Techniques based on HPLC have been widely used for the identification of hydrophilic phenolic compounds in olive oil and olive fruits (Mateos et al., 2004; Siliani et al., 2006; Kanakis et al., 2013; Mitsopoulos et al., 2016; Romero et al., 2017). The employment of UV methods, such as DAD, has seen a great use the past years for the quantitation of phenolics such as oleuropein, hydroxytyrosol and tyrosol (Boskou et al., 2005), phenolic acids and flavonoids (Artajo et al., 2007). It seems though that methods based on UV have a disadvantage because of their lack of sensitivity needed to measure the full range of hydrolysis products of oleuropein that appear during the processing of the table olives (Kumral et al., 2013). It is also mentioned that they are characterized by long time of separation and in most cases higher detection limits are required than MS methods to identify certain phenolics of the olive products (Segura-Carretero et al., 2010; Johnson et al., 2018). As a result, different methods have developed for the analysis of chemical compounds, such as mass spectrometry methods, which are more sensitive in detecting limits of quantification, than UV methods (Kanakis et al., 2013; Melliou et al., 2015; Johnson et al., 2018). MS methods seem to be more sensitive in the evaluation of hydrolysis products of oleuropein and they generally have been adopted for their higher sensitivity, selectivity, higher mass accuracy and the simultaneous quantitation in the analysis of phenolic compounds (Jerman Klen et al., 2015; Melliou et al., 2015; Johnson et al., 2018). MS methods have been focused mainly on studying olive oil (Bendini et al., 2007; Dierkes et al., 2012).

The aim of this research was to study the changes in the concentration of the most important phenolic compounds in the olive fruits cv 'Kalamata', one of the most important Greek table olive variety, that have been treated with two different, Greek-style and Spanish-style, processing methods. The study of the effect of the different processing methods on the phenolic compounds of the olive fruit was conducted by using two different methods of analysis and quantification, HPLC-(DAD) and LC-(ESI)-MS/MS.

\section{Materials and Methods}

\section{Olive fruit samples}

Three different styles of table olive fruits were included in the present study; fresh fruits, olives fruits processed in Greek-style method and olive fruits processed in Spanish-style method. All fruits were sampled from the same orchard in Agios Vlasios, region of Viotia, in November 2019 in the stage of full maturity and black color and from several trees in the orchard. For the processed table olive fruits, packages of 500 gr each were prepared, specifically for the study, and treated by a table olive production enterprise. Fruits processed with Greek-style method were placed in sodium chloride solution $10 \%$ with implementation of acetic acid. After this process, olives were exposed to oxygen conditions for 24 hours and finally were packed in fresh brine $8 \%$ and $\mathrm{pH}$ 4. Fruits processed with Spanish-style method were placed in sodium hydroxide solution 2\%. After this process, fruits were extracted, washed and placed in sodium chloride solution. Salt concentration in the solution was $6 \% \mathrm{w} / \mathrm{v}$. After the end of lactic fermentation, when the $\mathrm{pH}$ dropped to 4 , the salt concentration increased to $8 \%$. At their final stage of processing, the fruits were packed in fresh brine $8 \%$. Three replicates were made for each category of unprocessed and processed olive fruits, each sample included six fruits.

\section{Extraction method/Sample preparation}

The pit from the olive fruits was removed before the extraction. After pit removal, the flesh of the olive fruits was cut in small pieces and analytically weighted. The samples were homogenized with IKA Ultra-Turax T25 Basic, with $25 \mathrm{~mL}$-hexane, twice. Then, the samples were centrifuged for $10 \mathrm{~min}$ at $2500 \mathrm{xg}$ (in Labofuge 400 Functionline centrifuge), and the $n$-hexane layer was discarded. The residual solid phase was then extracted for $30 \mathrm{~min}$, in supersonic bath with $80 \%$ methanol for four times. Each time, the samples were centrifuged for 
$10 \mathrm{~min}$ at $2500 \mathrm{xg}$ and the extracts were transferred to $100 \mathrm{~mL}$ flasks. The volume was adjusted with $80 \%$ methanol. Sample preparation method was the same for the two different methods of analysis that were used.

\section{Identification and quantitation of phenolic compounds using the HPLC-(DAD) technique}

Identification and quantitation of the concentration of the phenolic compounds in the flesh of the olive fruit was performed using the HPLC-(DAD) technique, with the HPLC Agilent Technologies series 1200. Separation of the sample compounds was performed with a Zorbax Eclipse XDB-C18 rapid analysis column, $1.8 \mathrm{~mm}$, measuring $50 \mathrm{X} 4.6 \mathrm{~mm}$, maintained at $45^{\circ} \mathrm{C}$. The UV-Vis detector used was an Agilent Technologies series 1200 Diode-Array Detector (DAD). The sample was introduced into the analytical column via a Rheodyne model $7725 \mathrm{i}$ valve, with a circular volume of $20 \mathrm{~mL}$. The injection volume of the sample in the analytical column was $5 \mathrm{~mL}$.

Mobile phase consisted of $0.05 \%$ formic acid in deionized water (A) and methanol gradient grade (B) was delivered in gradient mode as follows: 0 min $25 \%$ B, 12 min 70\% B, 18 min 100\% B, 24 min 100\% B, with re-equilibration time $6 \mathrm{~min}$. Between analyses the column was rinsed with $2.2 \% \mathrm{v} / \mathrm{v}$ acetic acid solution. A 40min cleaning program was used to clean the column at regular intervals as follows: $10 \mathrm{~min}-100 \%$ acetic acid solution, $10 \mathrm{~min}-100 \%$ acetonitrile solution, $10 \mathrm{~min}-100 \%$ acetic acid solution. The wavelength switching program was adjusted in the DAD detector, based on the UV spectra of the phenolic compounds detected in the sample. The identification of each compound was done after comparing the sample peaks with standard phenolic compounds. The eluting phenolic compounds were detected in the range of 280 to $340 \mathrm{~nm}$. The quantitation of the above phenolic compounds identified in the samples was performed using commercial standards for these compounds, using a standard phenolic curve, for each of the compounds used. The assay was expressed as $\mu \mathrm{g}$ of phenolic compounds per gram of olive fruit fresh tissue. Quantitation of the identified phenolic compounds was performed according to the method of the external standard.

\section{Identification and quantitation of phenolic compounds using the LC-(ESI)-MS/MS technique}

The identification and quantitation of the individual phenolic compounds of the olive fruit tissue was performed using the reverse Twin Mass Spectrometry technique with electrospray ionization (LC-(ESI)MS/MS). The analyses were performed with the Agilent Technologies series 1260 HPLC system Agilent Technologies 6460 Triple-Quad Mass Detector, with electrospray ion source. The chromatographic column used was reverse phase, which had as filler material silanol groups chemically linked to 18 carbon atom chains. More specifically, the separation of the sample compound was performed with a Zorbax Eclipse XDB-C18 rapid analysis column, measuring $50 \times 4.6 \mathrm{~mm}$, with a particle diameter of $1.8 \mathrm{~mm}$. The rapid analysis column used was kept at $50{ }^{\circ} \mathrm{C}$. The sample was inserted with a Hamilton HPLC syringe into the injector and the volume of the injected sample was $5 \mathrm{~mL}$. The measurements were recorded with the program Agilent Technologies MassHunter Workstation Software - Data Acquisition (ver. B.03.01).

Mobile phase consisted of $0.05 \%$ formic acid in deionized water (A) and methanol gradient grade (B) was delivered in gradient mode as follows: $0 \mathrm{~min} 25 \% \mathrm{~B}, 12 \mathrm{~min} 70 \% \mathrm{~B}, 18 \mathrm{~min} 100 \% \mathrm{~B}, 24 \mathrm{~min} 100 \% \mathrm{~B}$, with re-equilibration time $6 \mathrm{~min}$. Between analyses the column was rinsed with $2.2 \% \mathrm{v} / \mathrm{v}$ acetic acid solution. A 40min cleaning program was used to clean the column at regular intervals as follows: $10 \mathrm{~min}-100 \%$ acetic acid solution, $10 \mathrm{~min}-100 \%$ acetonitrile solution, $10 \mathrm{~min}-100 \%$ acetic acid solution. Detection of eluting compounds in the samples was performed through the system (ESI)-MS/MS, using the ion source parameters, as follows: nebulization gas (N2) pressure: $50 \mathrm{psi}$, drying gas (N2) flow: $10 \mathrm{~L} / \mathrm{min}$ and temperature: $350{ }^{\circ} \mathrm{C}$, capillary voltage: $4 \mathrm{kV}$, negative polarity. Data were obtained in dynamic ion default monitoring (SRM) mode. The specific optimized parameters for the phenolic compounds were used to obtain the data: precursor ion, ion produced, fragmentation tendency, collision tendency. The tendency of each compound was made after comparing the peaks of the sample with the peaks of standard phenolic compounds. For all compounds, peak areas were identified using Agilent MassHunter Workstation Software - Qualitative Analysis (ver. B.06.01). Calibration curves were plotted, sample concentrations were calculated using Microsoft Excel Software and 
expressed as $\mu \mathrm{g}$ of phenolic compounds per gram of olive fruit fresh tissue. The conditions for determination of phenolic compounds in the fruit of cv. 'Kalamata' using the LC-(ESI)-MS/MS method is presented in Table 1.

Table 1. LC-(ESI)-MS/MS conditions for determination of phenolic compounds in the fruit of cv. 'Kalamata'

\begin{tabular}{|l|c|c|c|c|c|}
\hline \multicolumn{1}{|c|}{ Compound } & $\begin{array}{c}\text { Molecular weight } \\
(\mathrm{Mw})\end{array}$ & $\begin{array}{c}\text { Fragmentor } \\
\text { voltage } \\
(\mathrm{vf})\end{array}$ & $\begin{array}{c}\text { Precursor ions } \\
(\mathrm{m} / \mathrm{z})\end{array}$ & $\begin{array}{c}\text { Product ions } \\
(\mathrm{m} / \mathrm{z})\end{array}$ & $\begin{array}{c}\text { Collision energy } \\
\text { (vcol) }\end{array}$ \\
\hline Hydroxytyrosol & 154 & 130 & 153 & 123 & 11 \\
\hline Tyrosol & 138 & 120 & 137 & 106 & 13 \\
\hline Verbascoside & 624 & 116 & 623 & 161 & 33 \\
\hline Rutin & 610 & 135 & 609 & 300 & 19 \\
\hline Oleuropein & 540 & 180 & 539 & 275 & 25 \\
\hline Luteolin & 286 & 135 & 285 & 133 & 42 \\
\hline
\end{tabular}

\section{Statistical analysis}

The effect of the phenolic concentration factor on the phenolic compounds examined at the different stage of the fruit with or without treatment, and the treatment method was assessed by one-way analysis of variance (ANOVA). The comparisons of phenolic compounds for all samples, of all stages of the olive fruit were made based on the method of honest significant difference (HSD, Post-hoc Test) of the method TukeyHSD. Statistical analyses were performed with JMP 15.0 software (SAS Institute, Cary, NC, USA) and XLSTAT 2020.3.1 software (Addinsoft).

\section{Results and Discussion}

The phenolic compounds that were identified and quantified, using both analytical methods, were hydroxytyrosol, tyrosol, verbascocide, rutin and luteolin (Figures 1,2). Oleuropein was identified, in low quantities, when using the LC-(ESI)-MS/MS analytical method.

Both processing methods used, Greek-style and Spanish-style, altered the phenolic compound concentration in 'Kalamata' olive fruits compared to untreated fruits (Table 2). In both analytical methods, a statistically significant increase in verbascoside and hydroxytyrosol concentration and a statistically significant decrease in rutin concentration was observed in both, Greek-style and Spanish-style, processed olive fruits (Figures 1, 2 and Tables 2, 3). Tyrosol concentration significantly decreased in all processed olive fruits when using the HPLC-(DAD) technique while the decrease in tyrosol concentration was statistically significant only in Greek-style processed olive fruits when using the LC-(ESI)-MS/MS technique. Luteolin concentration was significantly increased in all processed olive fruits when using the LC-(ESI)-MS/MS technique while there was no statistically significant change in its concentration when using the HPLC-(DAD) technique. Oleuropein was identified, in low quantities, only when using the LC-(ESI)-MS/MS analytical method and a decrease was observed in processed fruits that was statistically significant in the Spanish-style processed fruits. Verbascocide was the predominate phenolic compound in all processed olive fruits, while rutin was the predominate compound in fresh olive fruits (Tables 2,3). Verbascoside and hydroxytyrosol concentration was significantly higher in the Greek-style processed fruits when using the LC-(ESI)-MS/MS analytical method while no statistically significant difference was observed in the concentration of the other phenolic compounds between the Greek-style and Spanish-style processed olive fruits using both analytical methods. 
Salis C et al. (2021). Not Bot Horti Agrobo 49(2):12394
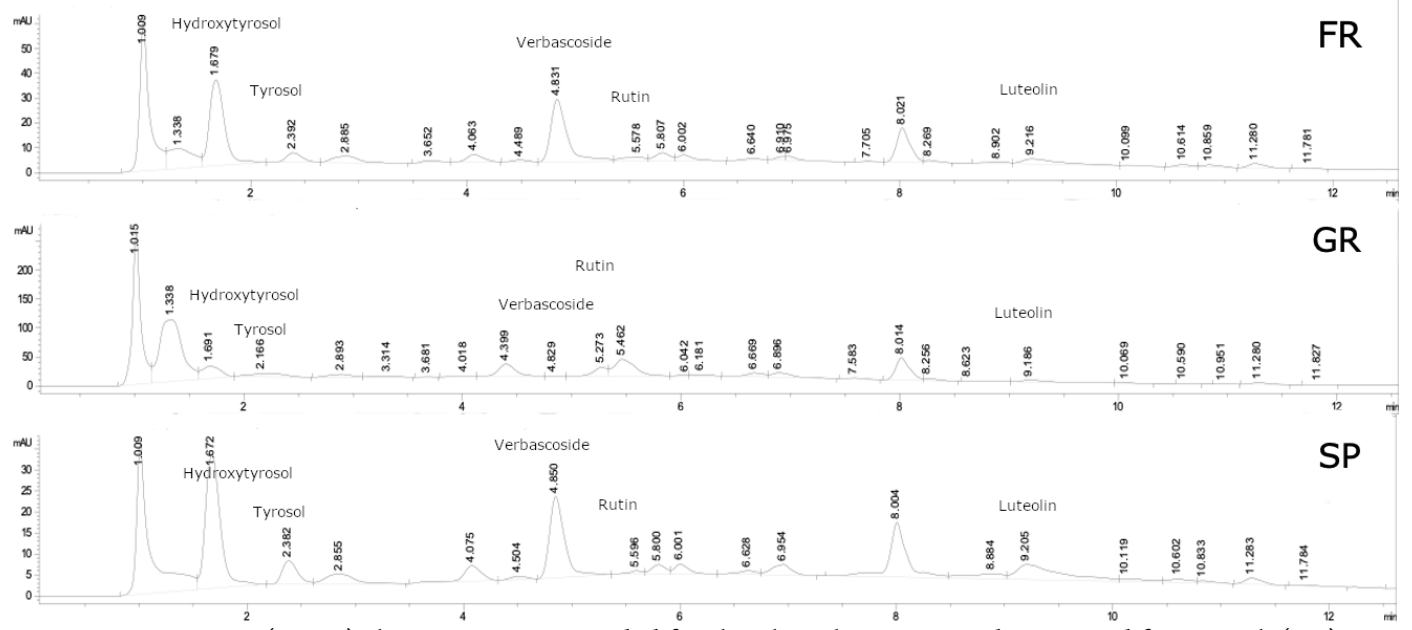

Figure 1. HPLC-(DAD) chromatogram recorded for the phenolic compounds extracted from Fresh (FR), Greek-style (GR) and Spanish-style (SP) olive fruits.
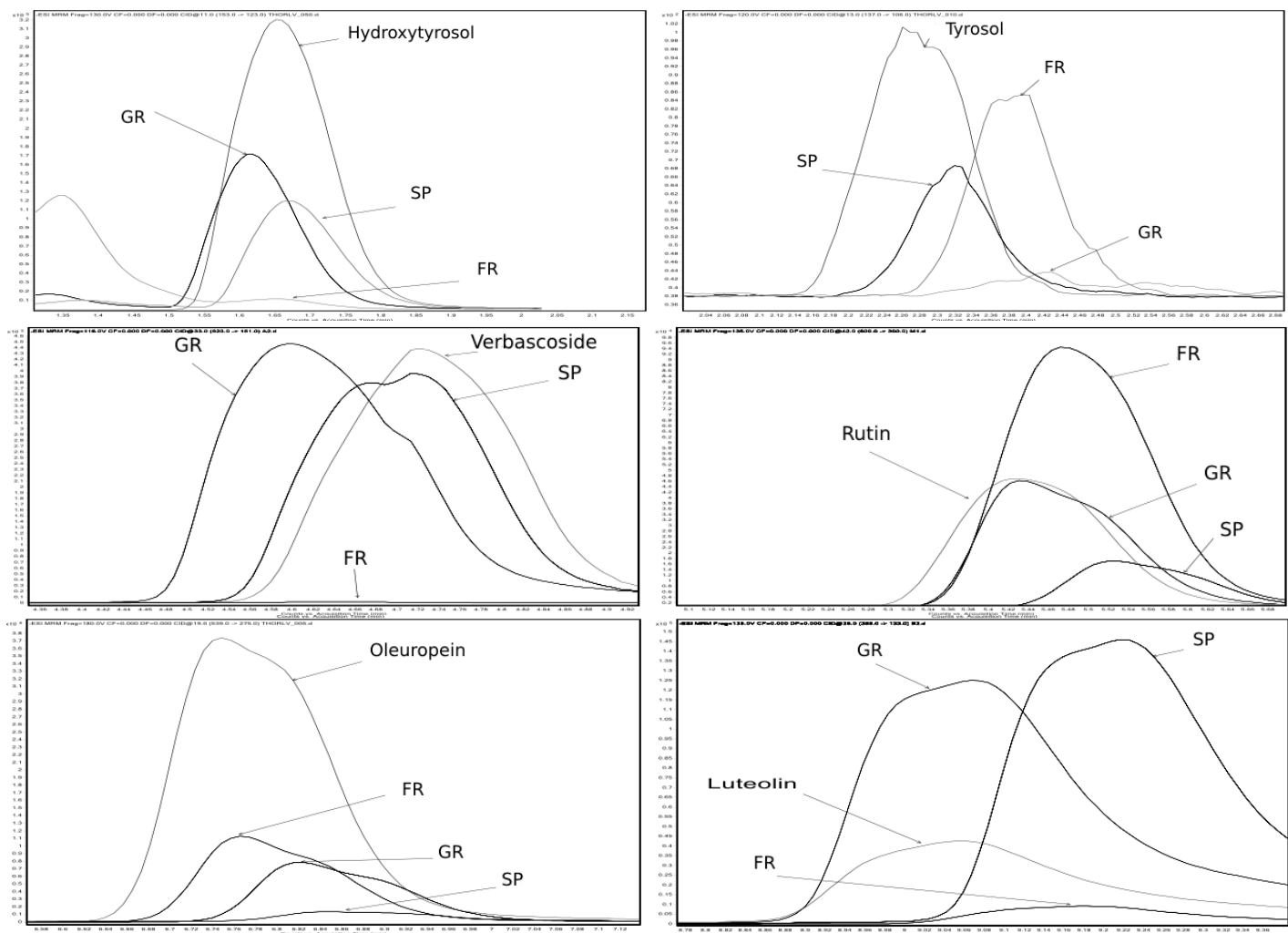

Figure 2. LC-(ESI)-MS/MS overlayed chromatogram of each phenolic compound extracted from Fresh (FR), Greek-style (GR) and Spanish-style (SP) olive fruits

Name $=$ standard compound

Verbascoside is a major derivative of hydrocinnamic acid in olive pulp and its presence is related to the variety and the harvest time (Charoenprasert and Mitchell, 2012). In this study, verbascoside concentration significantly increased in all processed olive fruits, using both analytical methods. Its concentration ranged from $31.50 \mu \mathrm{g} / \mathrm{g}$ fresh tissue $(\mathrm{ft})$ in unprocessed fruit to $504.26 \mu \mathrm{g} / \mathrm{g} \mathrm{ft}$ in Greek-style processed fruit using the HPLC-(DAD) analytical method and from $28.33 \mu \mathrm{g} / \mathrm{g} \mathrm{ft}$ in unprocessed fruit to $332.03 \mu \mathrm{g} / \mathrm{g} \mathrm{ft}$ in Greek-style 
processed fruit using the LC-(ESI)-MS/MS analytical method (Table 2). Verbascoside concentration was higher in the Greek-style than in the Spanish-style processed fruits, but the difference was statistically significant only when using the LC-(ESI)-MS/MS analytical method (Table 3). High verbascoside concentration in processed olive fruits was also observed by Melliou et al. (2015), Sahan et al. (2013) and Selli et al. (2018).

Table 2. Mean concentration of the phenolic compounds in tissue samples of fresh fruits (FR), Greek-style (GR) and Spanish-style (SP) treated olive fruits of cv. 'Kalamata', expressed in $\mu \mathrm{g}$ per $\mathrm{g}$ of fresh tissue

\begin{tabular}{|l|c|c|c|c|c|c|}
\hline \multirow{2}{*}{$\begin{array}{c}\text { Compound } \\
(\mu \mathrm{g} / \mathrm{gr})\end{array}$} & \multicolumn{3}{|c}{ HPLC-(DAD) } & \multicolumn{3}{c|}{ LC-(ESI)-MS/MS } \\
\cline { 2 - 8 } & FR & GR & SP & FR & GR & SP \\
\hline Hydroxytyrosol & $273.43 \pm 8.72$ & $367.83 \pm 32.53$ & $333.96 \pm 10.82$ & nq & $90.66 \pm 1.94$ & $63.10 \pm 2.62$ \\
\hline Tyrosol & $215.56 \pm 14.30$ & $84.33 \pm 1.99$ & $123.66 \pm 8.82$ & $37.23 \pm 4.39$ & $18.26 \pm 0.97$ & $27.93 \pm 0.76$ \\
\hline Verbascocide & $31.50 \pm 11.76$ & $504.26 \pm 39.49$ & $453.66 \pm 54.06$ & $28.33 \pm 6.65$ & $332.03 \pm 6.85$ & $283.80 \pm 6.92$ \\
\hline Rutin & $653.80 \pm 49.51$ & $5.50 \pm 0.78$ & $3.40 \pm 0.75$ & $296.03 \pm 24.06$ & $17.70 \pm 1.79$ & $6.63 \pm 0.38$ \\
\hline Oleuropein & nd & nd & nd & $7.66 \pm 1.13$ & $5.80 \pm 0.55$ & $2.90 \pm 0.90$ \\
\hline Luteolin & $106.06 \pm 9.12$ & $92.40 \pm 4.68$ & $118.16 \pm 8.45$ & $144.23 \pm 9.33$ & $228.2 \pm 14.18$ & $245.46 \pm 2.13$ \\
\hline
\end{tabular}

$\mathrm{nd}=$ non detected, $\mathrm{nq}=$ non quantifiable

Table 3. Comparison of samples of fresh (FR), Greek-style (GR) and Spanish-style (SP) samples

\begin{tabular}{|l|c|c|c|c|c|c|}
\hline \multirow{2}{*}{ Compound } & \multicolumn{3}{|c|}{ HPLC-(DAD) } & \multicolumn{3}{c|}{ LC-(ESI)-MS/MS } \\
\cline { 2 - 7 } & GR-FR & SP-FR & GR-SP & GR-FR & SP-FR & GR-SP \\
\hline Hydroxytyrosol & $*$ & $*$ & $\mathrm{~ns}$ & $* * *$ & $* * *$ & *** \\
\hline Tyrosol & $* * *$ & $* *$ & $\mathrm{~ns}$ & $* *$ & $\mathrm{~ns}$ & $\mathrm{~ns}$ \\
\hline Verbascocide & $* * *$ & $* *$ & $\mathrm{~ns}$ & $* * *$ & $* * *$ & ns \\
\hline Rutin & $* * *$ & $* * *$ & $\mathrm{~ns}$ & $* * *$ & $* * *$ & $\mathrm{~ns}$ \\
\hline Oleuropein & - & - & - & $\mathrm{ns}$ & $*$ & $\mathrm{~ns}$ \\
\hline Luteolin & $\mathrm{ns}$ & $\mathrm{ns}$ & $\mathrm{ns}$ & $* *$ & $* *$ & \multirow{2}{*}{} \\
\hline
\end{tabular}

${ }^{2}$ Significant set at $\alpha<0.05$. ns $=$ not significant, significance level ${ }^{*}<0.05,{ }^{* *}<0.01,{ }^{* * *}<0.001$.

Tukey HSD Post-hoc Test, One-way Analysis of Variance ANOVA.

Hydroxytyrosol concentration in the present study ranged from $273.43 \mu \mathrm{g} / \mathrm{g} \mathrm{ft}$ in unprocessed fruit to $367.83 \mu \mathrm{g} / \mathrm{g} \mathrm{ft}$ in Greek-style processed fruit using the HPLC-(DAD) analytical method (Table 2). Using the LC-(ESI)-MS/MS analytical method, hydroxytyrosol was detected in minute, non-measurable quantities, in fresh fruits while its concentration increased in the processed fruits, $63.10 \mu \mathrm{g} / \mathrm{g} \mathrm{ft}$ and $90.66 \mu \mathrm{g} / \mathrm{g} \mathrm{ft}$ in Spanishstyle and Greek-style respectively. There was a statistically significant increase of hydroxytyrosol concentration in processed fruits compared to the fresh fruits (Table 3). The concentration was higher in the Greek-style than in the Spanish-style processed olive fruits but the difference was statistically significant only when using the LC-(ESI)-MS/MS analytical method. Increase in hydroxytyrosol concentration in processed olive fruits was also reported by Marsilio et al. (2001) while higher hydroxytyrosol concentration was observed in Greek-style processed olive fruits (Marsilio et al., 2005; Johnson et al., 2018).

Luteolin concentration ranged from $92.40 \mu \mathrm{g} / \mathrm{g} \mathrm{ft}$ in Greek-style processed fruit to $118 \mu \mathrm{g} / \mathrm{g} \mathrm{ft}$ in Spanish-style processed fruit when using the HPLC-(DAD) analytical method and from $144.23 \mu \mathrm{g} / \mathrm{g} \mathrm{ft}$ in fresh fruits to $245.46 \mu \mathrm{g} / \mathrm{g} \mathrm{ft}$ in Spanish-style processed fruit when using the LC-(ESI)-MS/MS analytical method (Table 2). Its concentration was significantly increased in Greek-style and Spanish-style processed olive fruits when using the LC-(ESI)-MS/MS technique (Table 3) while there was no statistically significant difference in its concentration between the Greek-style and Spanish-style processed olive fruits. There was no significant difference in luteolin concentration between all fruits when using the HPLC-(DAD) analytical method. In a 
similar study, increase in luteolin concentration in processed fruit was reported (Ambra et al., 2017) while Melliou et al. (2015) reported that luteolin concentration was similar in fresh and processed fruits.

Rutin, according to the literature, is the major flavonoid in the olive fruit and this compound is always present, even when other compounds are absent (Esti et al., 1998; Servili et al., 2004). A statistically significant decreased in rutin concentration of processed fruits was observed using both analytical methods. Rutin concentration ranged from $3.40 \mu \mathrm{g} / \mathrm{g} \mathrm{ft}$ in Spanish-style processed fruits to $653.80 \mu \mathrm{g} / \mathrm{g} \mathrm{ft}$ in fresh fruit when using the HPLC-(DAD) analytical method and from $6.63 \mu \mathrm{g} / \mathrm{g} \mathrm{ft}$ in Spanish-style processed fruits to 296.03 $\mu \mathrm{g} / \mathrm{g} \mathrm{ft}$ in fresh fruits when using the LC-(ESI)-MS/MS technique (Table 3). There was no statistically significant difference in rutin concentration between Greek-style and Spanish-style processed fruits using both analytical methods. Many studies report a decrease in rutin concentration in processed olive fruits (BrenesBalbuena et al., 1992; Marsilio et al., 2005; Melliou et al., 2015). Vinha et al. (2005) and Mitsopoulos et al. (2016) report high rutin concentration in fresh olive fruits.

Tyrosol concentration ranged from $84.33 \mu \mathrm{g} / \mathrm{g} \mathrm{ft}$ in Greek-style processed fruits to $215.58 \mu \mathrm{g} / \mathrm{g} \mathrm{ft}$ in fresh fruits when using the HPLC-(DAD) analytical method and from $18,26 \mu \mathrm{g} / \mathrm{g} \mathrm{ft}$ in Greek-style processed fruits to $37,23 \mu \mathrm{g} / \mathrm{g} \mathrm{ft}$. in fresh fruits when using the LC-(ESI)-MS/MS technique (Table 3). Tyrosol concentration significantly decreased in all processed olive fruits when using the HPLC-(DAD) technique while the decrease in tyrosol concentration was statistically significant only in Greek-style processed olive fruits when using the LC-(ESI)-MS/MS technique. Brenes-Balbuena et al. (1992) also observed a decrease in tyrosol concentration in processed olive fruits.

Oleuropein is among the most important phenolic compounds found in the olive fruit. In our study, using the LC-(ESI)-MS/MS technique, oleuropein was detected in low concentration in all samples and a reduction in oleuropein concentration was observed in the processed fruits that was statistically significant in the Spanish style processed fruit (Table 3). Oleuropein concentration ranged from $2.90 \mu \mathrm{g} / \mathrm{g} f \mathrm{ft}$ in the Spanishstyle processed fruits to $7.66 \mu \mathrm{g} / \mathrm{g} \mathrm{ft}$ in fresh fruits. Decrease in oleuropein concentration in processed olive fruits was also reported from Ambra et al. (2017) and Johnson et al. (2018), while higher concentration of oleuropein in Greek-style than Spanish-style processed fruits was also reported (Brenes-Balbuena et al., 1992; Marsilio et al., 2001; Johnson et al., 2018).

Comparing the two processing methods used it was observed that verbascoside and hydroxytyrosol concentration was significantly higher in the Greek-style processed fruits when using the LC-(ESI)-MS/MS analytical method (Tables 2, 3) while no statistically significant difference was observed in the concentration of the other phenolic compounds between the Greek-style and Spanish-style processed olive fruits using both analytical methods. Studies comparing the two processing methods have shown higher phenolic compound concentration in the Greek-style than Spanish-style processed olive fruits (Blekas et al., 2002; Marsilio et al., 2005; D’Antuono et al., 2016; Johnson et al., 2018).

Comparing the two analytical methods used, some differences were observed. Using the HPLC-(DAD) technique, oleuropein was not detected in the olive fruits (Table 3). UV techniques are characterized for long separation times and for higher detection and quantitation limits, than MS techniques, that do not support the identification of specific phenolic compounds in olive products (Segura-Carretero et al., 2010). LC-MS/MS methods have higher sensitivity in the analysis of phenolic compounds (Segura-Carretero et al., 2010; Jerman Klen et al., 2015; Melliou et al., 2015; Johnson et al., 2018) and the LC-MS/MS method has reported good results with low quantification limits in the phenolic compounds analysis (Lopez-Fernandez et al., 2020).

\section{Conclusions}

In the present study, changes in the concentration of the most important phenolic compounds were quantified in fresh, Greek-style and Spanish-style processed olive fruits of cv. 'Kalamata', using two different analytical methods for identification and quantitation: high-performance liquid chromatography diode array 
detector (HPLC-DAD) and ultrahigh-performance liquid chromatography tandem mass spectrometry (LC(ESI)-MS/MS). The phenolic compounds that were identified and quantified were hydroxytyrosol, tyrosol, verbascocide, rutin, oleuropein and luteolin.

In both analytical methods, a statistically significant increase in verbascoside and hydroxytyrosol concentration and a statistically significant decrease in rutin concentration was observed in both, Greek-style and Spanish-style, processed olive fruits. Tyrosol concentration significantly decreased in all processed olive fruits when using the HPLC-(DAD) technique while the decrease in tyrosol concentration was statistically significant only in Greek-style processed olive fruits when using the LC-(ESI)-MS/MS technique. Luteolin concentration was significantly increased in all processed olive fruits when using the LC-(ESI)-MS/MS technique while there was no statistically significant change in its concentration when using the HPLC-(DAD) technique. Oleuropein was identified, in low quantities, only when using the LC-(ESI)-MS/MS analytical method and a decrease was observed in processed fruits that was statistically significant in the Spanish-style processed fruits. Verbascocide was the predominate phenolic compound in all processed olive fruits, while rutin was the predominate compound in fresh olive fruits.

Verbascoside and hydroxytyrosol concentration was significantly higher in the Greek-style processed fruits when using the LC-(ESI)-MS/MS analytical method while no statistically significant difference was observed in the concentration of the other phenolic compounds between the Greek-style and Spanish-style processed olive fruits using both analytical methods.

Although there were differences among the phenolic compound quantities detected using the two analytical methods, similar trends were observed between untreated/treated olive fruits.

Overall, both processing methods used altered the phenolic compounds concentration in 'Kalamata'

olive fruits compared to untreated fruits. The phenolic compounds are key contributors to the antioxidant properties of the olive fruit and these results can be useful for producing commercial products with beneficial health properties.

\section{Authors' Contributions}

Conceptualization: MH; Data curation: CS; Formal analysis: CS; Investigation: CS, MH and IEP; Methodology: MH and IEP; Project administration: MH; Resources: MH, IEP, and CS; Supervision: $\mathrm{MH}$ and IEP; Validation: MH, IEP, CS; Visualization: $\mathrm{MH}$; Writing-original draft: CS; Writing-review and editing: $\mathrm{CS}, \mathrm{MH}$ and IEP. All authors read and approved the final manuscript.

\section{Acknowledgements}

This research received no specific grant from any funding agency in the public, commercial, or not-forprofit sectors.

\section{Conflict of Interests}

The authors declare that there are no conflicts of interest related to this article. 


\section{References}

Akdemir Z, Kahraman, Ç, Tatlı I. I, Akkol E, K., Süntar I, Keles H (2011). Bioassay-guided isolation of antiinflammatory, antinociceptive and wound healer glycosides from the flowers of Verbascum mucronatum Lam. Journal of Ethnopharmacology 136(3):436-443. https://doi.org/10.1016/j.jep.2010.05.059

Ambra R, Natella F, Bello C, Lucchetti S, Fort V, Pastore G (2017). Phenolics fate in table olives (Olea europaea L. cv. Nocellara del Belice) debittered using the Spanish and Castelvetrano methods. Food Research International 100:369-376. https://doi.org/10.1016/j.foodres.2017.07.027

Artajo LS, Romero MP, Suárez M (2007). Partition of phenolic compounds during the virgin olive oil industrial extraction process. European Food Research Technology 225:617-625. https://doi.org/10.1007/s00217-0060456-0

Barbaro B, Toietta G, Maggio R, Arciello M, Tarocchi M, Galli A, Balsano C (2014). Effects of the olive-derived polyphenol oleuropein on human health. International Journal of Molecular Sciences 15(10):18508-18524. https://doi.org/10.3390/ijms151018508

Bartolini G, Petruccelli R (2002). Classification, origin, diffusion and history of the olive. Food \& Agriculture Org.

Basdeki E, Salis C, Hagidimitriou M (2020). The effects of Mediterranean diet and EVOO consumption in relation to human health. Notulae Scientia Biologicae 12(3):466-485. http://doi.org/10.15835/nsb123107

Bendini A, Cerretani L, Carrasco-Pancorbo A, Gómez-Caravaca AM, Segura-Carretero A, Fernández-Gutiérrez A, Lercker G (2007). Phenolic molecules in virgin olive oils: a survey of their sensory properties, health effects, antioxidant activity and analytical methods. An overview of the last decade Alessandra. Molecules 12(8):16791719. https://doi.org/10.3390/12081679

Bianco A, Buiarelli F, Cartoni G, Coccioli F, Jasionowska R, Margherita P (2003). Analysis by liquid chromatographytandem mass spectrometry of biophenolic compounds in olives and vegetation waters. Part I. Journal of Separation Science 26(5):409-416. https://doi.org/10.1002/jssc.200390053

Blekas G, Vassilakis C, Harizanis C, Tsimidou M, Boskou DG (2002). Biophenols in table olives. Journal of Agricultural and Food Chemistry 50(13):3688-3692. https://doi.org/10.1021/jfo115138

Boskou D, Blekas G, Tsimidou M (2005). Phenolic compounds in olive oil and olives. Current Topics in Nutraceutical Research 3(2):125-136.

Brenes-Balbuena M, Garcia-Garcia P, Garrido-Fernandez A (1992). Phenolic compounds related to the black color formed during the processing of ripe olives. Journal of Agricultural and Food Chemistry 40(7):1192-1196. https://doi.org/10.1021/jfo0019a023

Carrasco-Pancorbo A, Neusüß C, Pelzing M, Segura-Carretero A, Fernández-Gutiérrez A (2007). CE-and HPLC-TOFMS for the characterization of phenolic compounds in olive oil. Electrophoresis 28(5):806821. https://doi.org/10.1002/elps.200600382

Charoenprasert S, Mitchell A (2012). Factors influencing phenolic compounds in table olives (Olea europaea). Journal of Agricultural and Food Chemistry 60(29):7081-7095. https://doi.org/10.1021/jf3017699

Chang CY, Huang IT, Shih HJ, Chang YY, Kao MC, Shih PC, Huang CJ (2019). Cluster of differentiation 14 and tolllike receptor 4 are involved in the anti-inflammatory effects of tyrosol. Journal of Functional Foods 53:93-104. https://doi.org/10.1016/j.jff.2018.12.011

Cicerale S, Lucas LJ, Keast RSJ (2012). Antimicrobial, antioxidant and anti-inflammatory phenolic activities in extra virgin olive oil. Current Opinion in Biotechnology 23(2):129-135. https://doi.org/10.1016/j.copbio.2011.09.006

D’Antuono I, Garbetta A, Ciasca B, Linsalata V, Minervini F, Lattanzio VM, Cardinali A (2016). Biophenols from table olive cv Bella di Cerignola: Chemical characterization, bioaccessibility, and intestinal absorption. Journal of Agricultural and Food Chemistry 64(28):5671-5678. https://doi.org/10.1021/acs.jafc.6b01642

Di Benedetto R, Varì R, Scazzocchio B, Filesi C, Santangelo C, Giovannini C, Masella R (2007). Tyrosol, the major extra virgin olive oil compound, restored intracellular antioxidant defences in spite of its weak antioxidative effectiveness. Nutrition, Metabolism and Cardiovascular Diseases 17(7):535-545. https://doi.org/10.1016/j.numecd.2006.03.005

Dierkes G, Krieger S, Dück R, Bongartz A, Schmitz OJ, Hayen H (2012). High-performance liquid chromatographymass spectrometry profiling of phenolic compounds for evaluation of olive oil bitterness and pungency. Journal of Agricultural and Food Chemistry 60(31):7597-7606. https://doi.org/10.1021/jf3020574 
Esti M, Cinquanta L, La Notte E (1998). Phenolic compounds in different olive varieties. Journal of Agricultural and Food Chemistry 46:32-35. https://doi.org/10.1021/jf970391+

Fu S, Segura-Carretero A, Arraez-Roman D, Menendez JA, De La Torre A, Fernandez-Gutierrez A (2009). Tentative characterization of novel phenolic compounds in extra virgin olive oils by rapid-resolution liquid chromatography coupled with mass spectrometry. Journal of Agricultural and Food Chemistry 57(23):1114011147. https://doi.org/10.1021/jf901590n

Gerber M, Hoffman R (2015). The Mediterranean diet: health, science and society. British Journal of Nutrition 113(S2):S4-S10. https://doi.org/10.1017/S0007114514003912

Hassen I, Casabianca H, Hosni K (2015). Biological activities of the natural antioxidant oleuropein: Exceeding the expectation - A mini-review. Journal of Functional Foods 18:926-940. https://doi.org/10.1016/j.jff.2014.09.001

Janbaz KH, Saeed SA, Gilani A (2002). Protective effect of rutin on paracetamol-and CCl4-induced hepatotoxicity in rodents. Fitoterapia 73(7-8):557-563. https://doi.org/10.1016/S0367-326X(02)00217-4

Javed H, Khan MM, Ahmad A, Vaibhav K, Ahmad ME, Khan A, Safhi MM (2012). Rutin prevents cognitive impairments by ameliorating oxidative stress and neuroinflammation in rat model of sporadic dementia of Alzheimer type. Neuroscience 210:340-352. https://doi.org/10.1016/j.neuroscience.2012.02.046

Jerman Klen T, Golc Wondra A, Vrhovšek U, Mozetič Vodopivec B (2015). Phenolic profiling of olives and olive oil process-derived matrices using UPLC-DAD-ESI-QTOF-HRMS analysis. Journal of Agricultural and Food Chemistry 63(15):3859-3872. https://doi.org/10.1021/jf506345q

Johnson R, Melliou E, Zweigenbaum J, Mitchell AE (2018). Quantitation of oleuropein and related phenolics in cured Spanish-style green, California-style black ripe, and Greek-style natural fermentation olives. Journal of Agricultural and Food Chemistry 66(9):2121-2128. https://doi.org/10.1021/acs.jafc.7b06025

Kanakis P, Termentzi A, Michel T, Gikas E, Halabalaki M, Skaltsounis AL (2013). From olive drupes to olive oil. An HPLC-orbitrap-based qualitative and quantitative exploration of olive key metabolites. Planta Medica 79(16):1576-1587. http://dx.doi.org/10.1055/s-0033-1350823

Karakaya S, Nehir ElS (1999). Quercetin, luteolin, apigenin and kaempferol contents of some foods. Food Chemistry 66:289-292. https://doi.org/10.1016/S0308-8146(99)00049-7

Karkoula E, Skantzari A, Melliou E, Magiatis P (2012). Direct measurement of oleocanthal and oleacein levels in olive oil by quantitative $1 \mathrm{H}$ NMR. Establishment of a new index for the characterization of extra virgin olive oils. Journal of Agricultural and Food Chemistry 60(47):11696-11703. https://doi.org/10.1021/jf3032765

Khalatbary AR (2013). Olive oil phenols and neuroprotection. Nutritional Neuroscience 16(6):243-249. https://doi.org/10.1179/1476830513Y.0000000052

Kingston DG (2011). Modern natural products drug discovery and its relevance to biodiversity conservation. Journal of Natural Products 74(3):496-511. https://doi.org/10.1021/np100550t

Korkina LG (2007). Phenylpropanoids as naturally occurring antioxidants: from plant defense to human health. Cellular and Molecular Biology 53(1):15-25.

Kumral A, Korukluoglu M, Romero C, de Castro A, Ruiz-Barba JL, Brenes M (2013). Phenolic inhibitors involved in the natural fermentation of Gemlik cultivar black olives. European Food Research and Technology 236(1):101-107. https://doi.org/10.1007/s00217-012-1859-8

Lee JH, Lee JY, Kang HS, Jeong CH, Moon H, Whang WK, Sim SS (2006). The effect of acteoside on histamine release and arachidonic acid release in RBL-2H3 mast cells. Archives of Pharmacological Research 29(6):508. https://doi.org/10.1007/BF02969425

Lenoir L, Rossary A, Joubert-Zakeyh J, Vergnaud-Gauduchon J, Farges MC, Fraisse D, Felgines C (2011). Lemon verbena infusion consumption attenuates oxidative stress in dextran sulfate sodium-induced colitis in the rat. Digestive Diseases and Sciences 56(12):3534-3545. https://doi.org/10.1007/s10620-011-1784-X

Lin Y, Shi R, Wang X, Shen HM (2008). Luteolin, a flavonoid with potential for cancer prevention and therapy. Current Cancer Drug Targets 8(7):634-646. https://doi.org/10.2174/156800908786241050

López-Fernández O, Domínguez R, Pateiro M, Munekata P, Rocchetti G, Lorenzo JM (2020). Determination of polyphenols using liquid chromatography-tandem mass spectrometry technique (LC-MS/MS): A review. Antioxidants 9(6):479. https://doi.org/10.3390/antiox9060479

Mazza G, Miniati E (1993). Anthocyanins in fruits, vegetables and grains Boca Raton, FL: CRC Press, pp 64-67.

Melliou E, Zweigenbaum JA, Mitchell AE (2015). Ultrahigh-pressure liquid chromatography triple-quadrupole tandem mass spectrometry quantitation of polyphenols and secoiridoids in California-style black ripe olives and dry salt- 
Salis C et al. (2021). Not Bot Horti Agrobo 49(2):12394

cured olives. Journal of Agricultural and Food Chemistry 63(9):2400-2405. https://doi.org/10.1021/jf506367e

Mitsopoulos G, Papageorgiou V, Komaitis M, Hagidimitriou M (2016). Phenolic profile of leaves and drupes of ten olive varieties. Notulae Botanicae Horti Agrobotanici Cluj-Napoca 44(1):162-166. https://doi.org/10.15835/nbha44110382

Nassiri-Asl M, Mortazavi SR, Samiee-Rad F, Zangivand AA, Safdari F, Saroukhani S, Abbasi E (2010). The effects of rutin on the development of pentylenetetrazole kindling and memory retrieval in rats. Epilepsy \& Behavior 18(12):50-53. https://doi.org/10.1016/j.yebeh.2010.03.005

Parkinson L, Cicerale S (2016). The health benefiting mechanisms of virgin olive oil phenolic compounds. Molecules 21(12):1734. https://doi.org/10.3390/molecules21121734

Qiao H, Zhang X, Zhu C, Dong L, Wang L, Zhang X, Cao X (2012). Luteolin downregulates TLR4, TLR5, NF- $\kappa$ B and p-p38MAPK expression, upregulates the p-ERK expression, and protects rat brains against focal ischemia. Brain Research 1448:71-81. https://doi.org/10.1016/j.brainres.2012.02.003

Richetti SK, Blank M, Capiotti KM, Piato AL, Bogo MR, Vianna MR, Bonan CD (2011). Quercetin and rutin prevent scopolamine-induced memory impairment in zebrafish. Behavioral Brain Research 217(1):10-15. https://doi.org/10.1016/j.bbr.2010.09.027

Rigacci S, Stefani M (2016). Nutraceutical properties of olive oil polyphenols. An itinerary from cultured cells through animal models to humans. International Journal of Molecular Sciences 17(6):843. https://doi.org/10.3390/ijms17060843

Robles-Almazan M, Pulido-Moran M, Moreno-Fernandez J, Ramirez-Tortosa C, Rodriguez-Garcia C, Quiles JL, Ramirez-Tortosa M (2018). Hydroxytyrosol: Bioavailability, toxicity, and clinical applications. Food Research International 105:654-667. https://doi.org/10.1016/j.foodres.2017.11.053

Romani A, Mulinacci N, Pinelli P, Vincieri FF, Cimato A (1999). Polyphenolic content in five Tuscany cultivars of Olea europaea L. Journal of Agricultural and Food Chemistry 47:964-967. https://doi.org/10.1021/jf980264t

Romero C, Brenes M, Garcia P, Garrido A (2002). Hydroxytyrosol 4- $\beta$-D- glucoside, an important phenolic compound in olive fruits and derived products. Journal of Agricultural and Food Chemistry 50:3835-3839. https://doi.org/10.1021/jfo11485t

Romero C, Medina E, Mateo MA, Brenes M (2017). Quantification of bioactive compounds in Picual and Arbequina olive leaves and fruit. Journal of the Science of Food and Agriculture 97(6):1725-1732. https://doi.org/10.1002/jsfa.7920

Ryan D, Robards K (1998). Phenolic compounds in olives. Analyst 123:31-44.

Sahan Y, Cansev A, Gulen H (2013). Effect of processing techniques on antioxidative enzyme activities, antioxidant capacity, phenolic compounds, and fatty acids of table olives. Food Science and Biotechnology 22(3):613-620. https://doi.org/10.1007/s10068-013-0122-9

Salas-Salvadó J, Bulló M, Estruch R, Ros E, Covas MI, Ibarrola-Jurado N, Romaguera D (2014). Prevention of diabetes with Mediterranean diets: a subgroup analysis of a randomized trial. Annals of internal medicine 160(1):1-10. https://doi.org/10.7326/M13-1725

Salis C, Papageorgiou L, Papakonstantinou E, Hagidimitriou M, Vlachakis D (2020). Olive Oil Polyphenols in Neurodegenerative Pathologies. In: Vlamos P (Ed). GeNeDis 2018. Advances in Experimental Medicine and Biology. Vol 1195. Springer, Cham. https://doi.org/10.1007/978-3-030-32633-3_12

Segura-Carretero A, Carrasco-Pancorbo A, Bendini A, Cerretani L, Fernández-Gutiérrez A (2010). Analytical determination of polyphenols in olive oil. In: Olives and olive oil in health and disease prevention. Academic Press, pp 509-523. https://doi.org/10.1016/B978-0-12-374420-3.00056-5

Selli S, Kelebek H, Kesen S, Sonmezdag AS (2018). GC-MS olfactometric and LC-DAD-ESI-MS/MS characterization of key odorants and phenolic compounds in black dry-salted olives. Journal of the Science of Food and Agriculture 98(11):4104-4111. https://doi.org/10.1002/jsfa.8927

Servili M, Selvaggini R, Esposto S, Taticchi A, Montedoro G, Morozzi G (2004). Health and sensory properties of virgin olive oil hydrophilic phenols: agronomic and technological aspects of production that affect their occurrence in the oil. Journal of Chromatography A 1054(1-2):113-127. https://doi.org/10.1016/j.chroma.2004.08.070

Siliani S, Mattei A, Innocenti LB, Zanoni B (2006). Bitter taste and phenolic compounds in extra virgin olive oil: an empirical relationship. Journal of Food Quality 29(4):431-441. https://doi.org/10.1111/j.17454557.2006.00084.x 
Soler-Rivas C, Espin JC, Wichers HJ (2000). Oleuropein and related compounds. Journal of the Science of Food and Agriculture 80:1013-1023. https://doi.org/10.1002/(SICI)1097-0010(20000515)80:7<1013::AIDJSFA $571>3.0 . C O ; 2-C$

Theoharides TC, Stewart JM, Hatziagelaki E (2015). Brain "fog”, inflammation and obesity: key aspects of neuropsychiatric disorders improved by luteolin. Frontiers in Neuroscience 9:225. https://doi.org/10.3389/fnins.2015.00225

Tomé-Carneiro J, Crespo MC, Iglesias-Gutierrez E, Martín R, Gil-Zamorano J, Tomas-Zapico C, Herrera E (2016). Hydroxytyrosol supplementation modulates the expression of miRNAs in rodents and in humans. The Journal of Nutritional Biochemistry 34:146-155. https://doi.org/10.1016/j.jnutbio.2016.05.009

Valenzuela R, Echeverria F, Ortiz M, Rincón-Cervera MÁ, Espinosa A, Hernandez-Rodas MC, Videla LA (2017). Hydroxytyrosol prevents reduction in liver activity of $\Delta-5$ and $\Delta-6$ desaturases, oxidative stress, and depletion in long chain polyunsaturated fatty acid content in different tissues of high-fat diet fed mice. Lipids in Health and Disease 16(1):64. https://doi.org/10.1186/s12944-017-0450-5

Vasto S, Barera A, Rizzo C, Di Carlo M, Caruso C, Panotopoulos G (2014). Mediterranean diet and longevity: an example of nutraceuticals? Current Vascular Pharmacology 12(5):735-738.

Vinha AF, Ferreres F, Silva BM, Valentao P, Gonçalves A, Pereira JA, Andrade PB (2005). Phenolic profiles of Portuguese olive fruits (Olea europaea L.): Influences of cultivar and geographical origin. Food Chemistry 89(4):561-568. https://doi.org/10.1016/j.foodchem.2004.03.012

Visioli F, Poli A, Gall C (2002). Antioxidant and other biological activities of phenols from olives and olive oil. Medicinal Research Reviews 22(1):65-75. https://doi.org/10.1002/med.1028

Zoidou E, Melliou E, Gikas E, Tsarbopoulos A, Magiatis P, Skaltsounis AL (2010). Identification of Throuba Thassos, a traditional Greek table olive variety, as a nutritional rich source of oleuropein. Journal of Agricultural and Food Chemistry 58(1):46-50. https://doi.org/10.1021/jf903405e
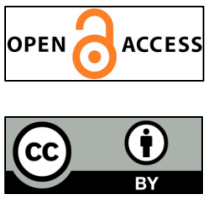

The journal offers free, immediate, and unrestricted access to peer-reviewed research and scholarly work. Users are allowed to read, download, copy, distribute, print, search, or link to the full texts of the articles, or use them for any other lawful purpose, without asking prior permission from the publisher or the author.

License - Articles published in Notulae Botanicae Horti Agrobotanici Cluj-Napoca are Open-Access, distributed under the terms and conditions of the Creative Commons Attribution (CC BY 4.0) License.

(c) Articles by the authors; UASVM, Cluj-Napoca, Romania. The journal allows the author(s) to hold the copyright/to retain publishing rights without restriction. 